DOI: 10.1515/ausfm-2016-0012

\title{
Hypertheatre or Media Entanglement in the Theatre of Jay Scheib
}

\author{
Mircea Valeriu Deaca \\ University of Bucharest (Romania) \\ E-mail: deaca@dnt.ro
}

\begin{abstract}
The theatre of Jay Scheib blends theatrical and filmic features, allowing for a theoretical investigation of the manner in which two different media coexist on the same expressive support. How can two distinct media like film and theatre fuse and, at the same time, be apprehended as separate artistic means in a single artifact? The present article uses a theoretical interpretive metaphor that rests on an application of the mechanisms of relationship between two physical systems issued from the quantum mechanical view of reality. From this perspective, the two afore-mentioned media are in an entangled state. Media is understood as "potential materials or forms for future practices," or "automatisms" (Rodowick 2007, 42). At the same time, theatrical or cinematic media is apprehended by the audience in a dynamic way, not defined as a static bundle of defining features. Dynamic conceptualization will modulate or "tune" the comprehension of one of the media considered to be a subordinate system in the duplex. The blending of the two media presupposes a local conceptualization unfolding dynamically and an entangled one manifested nonlocal. The distinction between film and theatre is also to be seen as a difference in the cognitive model which posits a detached display (a screen/a scene), an imaginary world (a diegesis) and a spectator (observer). In theatre, the body of the observer is inside the theatrical display setting, while in film, the body of the viewer is conceptualized to be separated from the cinematic display. The notion of threshold, introduced by Dudley Andrew (2010), renders this shift of attention from one side of the display to the other.
\end{abstract}

Keywords: theatre, film, media entanglement, automatism, cognitive approach, Jay Scheib. 


\section{Introduction}

The theatre of Jay Scheib ${ }^{1}$ presents the curious case of blending theatrical and filmic features, confronting the audience with a categorization conundrum: is this artifact theatre, film or a different category altogether, a hypertheatre? Scheib's performances, which can be considered live cinematic adaptations, use two alternative media in order to depict what will further be called diegesis, a virtual state of affairs. ${ }^{2}$ The performance event is achieved simultaneously, as a live play, carried out in a theatre, and as a feature film on a DVD, filmed and edited in real time during the performance. For the sake of simplicity, we will refer to the former as theatre ( $\mathrm{T}$ ) and to the latter as film (F). We use here Scheib's example in order to address some theoretical issues relevant to the cognitive approach of film analysis, and we do not propose an interpretation or a detailed analysis of his work. Scheib's work raises the questions of identity starting from the observation that out of the two artistic experiences neither one fully encompasses the whole artifact. Are we confronted with one work or artifact or two separate ones? Is his work T or F? If this is one work, what is its medial manifestation? Or should it be considered as an instance of the elimination of the above distinction? And if this is the case, are we confronted with a new media, which is neither F nor T? If so, what would its relation be to the constitutive categories $\mathrm{T}$ and $\mathrm{F}$, which, obviously, rise to awareness as distinctly conceptualized entities?

Scheib's play, This Place is a Desert (2007) stages a human drama unfolding in a setting of continuous video surveillance and pervasive digital image located inside and outside the diegetic world. The setting is composed of two rooms and a hallway. The left room opens into a veranda situated at the back of the stage, used mostly as a living room. In the room on the right there is a bed, thus it can be identified as a bedroom. Between the two, there is the hallway [Fig. 1]. Most of the scenes performed are restagings of Michelangelo Antonioni's films. Scenes and lines from his films are quoted extensively. The play's performance

1 Jay Scheib is director of Theater Arts at the Massachusetts Institute of Technology, where he teaches performance media, motion theater, media and methods, and introduction to directing. His cinematic adaptations are: World of Wires (2012), Bellona Destroyer of Cities (2010), Addicted to Bad Ideas, Peter Lorre's 20th Century (2009) or Platonov, or the Disinherited (2014). See http://jayscheib.com/; http://mta.mit.edu/person/jay-scheib and https://en.wikipedia.org/ wiki/Jay_Scheib. Last accessed 12.11. 2016.

2 Diegesis is understood as a fictional world where a character can dwell in (Odin 2000, 19; Buckland 2000, 92), as the "story action" (Bordwell 2008, 76), or as a semantic description elaborated out of perceptive data displayed on the cimematic screen (Branigan 1986, 44). In short, it is a mental imaginary construct elaborated with the use of perceptual cues. 
blends the features of both theatre and film. ${ }^{3}$ As spectators, we are confronted with a performance that transforms theatre into a living enactment of a film and film media into a theatrical performance. In a sense, this kind of performance re-enacts the "cinema of attractions" as defined by Tom Gunning (1986). For the early cinema - until 1906 -, the exhibition of the cinema itself (its technical and viewing possibilities) was an attraction in itself. Cinematic views were props inserted in a theatrical performance.

Starting from the frame of reference of the medial definition of theatre versus film, let us consider the manner in which the choice of intertextuality and cinematic quotation highlights the fact that Sheib's theatre is, from its starting point, a restaging of Antonioni's films. In some scenes, the actors are out of theatrical view - hidden behind walls -, but nonetheless their actions can be seen on the screens hanging from the ceiling. The screens are fed online by the static and mobile cameras positioned in and out of the theatrical stage that record continuously. Sometimes, in those scenes, characters are positioned in the depth of the camera field, in reminiscence of Michelangelo Antonioni's style or Orson Welles's depth frame [Fig. 2]. The 3D body compositions drawn by the actors on stage are intended to be fully comprehensible if one sees them from a specific cinematic frame and vantage point embedded in the theatrical diegesis. The optimum view to the drama is denied to the spectator situated in a theatrical vantage point. The spectators, seated in the theatrical hall, can see at times in vivo a wall that hides the drama but, as viewers, they can have visual access only to the cinematic screens that optically reveal the plot being carried out behind the wall. The multiscreen display is also a reference to Mike Figgis's film, Timecode (2000) [Fig. 3]. This vantage point is refused to the theatrical setting (to the audience in the theatre), but is accessible to the same audience perceptually and cognitively in a filmic setting, i.e. in front of a screen. In short, the audience is alternately prompted to experiment the performance in a theatrical mode as spectators and in a cinematic mode as viewers - both modes embedded in a single theatrical performance.

3 One could say that Sheib's play is a living enactment of the conceptual integration/conceptual blending process occurring between two different input mental spaces (Fauconnier 1985, 2002, 2007). 


\section{Some Theoretical Prerequisites}

\section{Type/Token/Template}

Seeing things from a specifically cognitive approach applied to film analysis, we can start by mentioning Noël Carroll's observations on the difference between theatre and film, which is based on the type/token distinction, i.e. concept versus object that instantiates the concept as its specific expression. "Specifically: live theatrical, token performances are generated by interpretations, whereas token performances of motion pictures are generated by templates" in the words of Carroll $(2008,65)$. For live theatre, the token performance is generated by an interpretation, a type. For mechanical cinema, the token performance is generated by a template. Also, according to Carroll, since theatre and film practices are different, the performance of motion picture is not an object of artistic assessment, whereas theatrical performances are. The token performance of cinema is not an artwork, while the theatre token performance is an artwork per se: "successful theatrical performance involves a token interpretation of an interpretation type" (Carroll 2008, 70). For Scheib, the distinction is blurred since in the theatre hall the audience witnesses a cinematic performance of the theatrical kind; an artistic instance of a cinematic performance. On the other hand, the DVD copy is a token of a particular instance of interpretation, a token that serves as a template. For Sheib's live adaptations, the theatrical token is also a template, and the audience is confronted with an artistic artifact that is at the same time token and type, token and template instantiated in a recursive manner. Therefore, the performance of cinema in the play performance is also an object of artistic assessment, since it is a constitutive part of the play performance as well.

\section{Medium According to Carroll}

According to Noël Carroll in The Philosophy of Motion Pictures (1996), cinematic media has a value as a communication instrument or has a meaning as a consequence of a particular use in a pragmatic context: "[o]n the issue of the essential nature of film, I hold that film has no essence, only uses, most of which are derivative and subject to analysis and evaluation according to the categories that apply to their sources - art, drama, narrative, nonfiction, and so on" (1996, 245). Also in Carroll's perspective, the "medium is a middleman, a go-between betwixt one thing and another." In his essay, Carroll proposes five distinctive 
features of moving images. Something is a moving picture if (1) it is a detached display, (2) it belongs to a class of things from which the impression of movement is technically possible, (3) its performance token is generated by a template that is a token, (4) its performance token is not an artwork in itself, and (5) it is bidimensional $(2008,35-51)$. Sheib's play blends Carroll's distinctive features in terms of the theatrical performance, where (1) theatre and film share the common feature of detached display (stage and screen make reference to a fictional diegesis), ${ }^{4}(2)$ both offer the impression of movement, (3) both are generated by a token that is theatrical (a unique performance) and filmic template (a recording device of indicial character in a Peircean manner of speaking) at the same time, ${ }^{5}$ (4) film and theatre in this instance are artworks in themselves, and (5) both are 3-dimensional artifacts. ${ }^{6}$

We can focus on Carroll's notion of detached display, common to film and theatrical media. Both media "display persons, places, things, actions, and events that are phenomenologically detached, in the preceding sense, from the actual space of our bodies" (Carroll 2008, 57) or in both cases "the referent of the display is discontinuous with, or detached or absent from, the space in which our eyes can plot the way to our destination" (Carroll 2008, 58). As put forth by Carroll in the quoted text, theatrical performance is also a detached display and is opposed to a local embodiment of diegesis (in a locale accessible to human body and within grasping distance).

Nevertheless, Carroll has recently revised his position and nowadays (2013, 2014) he considers that film cues draw attention - in a constricted way - to aspects described in the diegesis and, conversely, that theatre allows the spectator to freely direct his attention towards the 3D diegetic space. In a sense, the detached

$4 \quad$ Sheib also blurs the line between documentary and fictional discourse. Online screen projections create the documentary of the performance, while generating a fictional world. The performance is, in itself, a fiction on the DVD copy of the play and, on the theatrical stage, it is part of the fictional world depicted by the play. The play depicts a fictional world where one reality (the theatrical diegesis or the drama enacted by the actor's performance on the stage) is recorded by several filmic cameras. The fictional world is a world of recorded reality. Camera recording and screening are as fictional as the drama that the actors are enacting unaware of them being recorded. Conversely, the DVD copy can be seen as depicting a fictional realm (the making of a film) or a real one (the documentary of the making of the film). In the end, the DVD copy makes the documentary of the fictional world called here recorded reality. Origin, copy and the continuous generation of simulacra are put to the fore in a programmatic fashion (for example in Jacques Derrida and Jean Baudrillard's poststructuralist literature).

$5 \quad$ Filmic template in Scheib's work is not an immutable type, but is causally dependent upon the actual unique performance of the actors on the night of the play. Each night has another film attached to it.

$6 \quad$ Filmic screens in the play performance are 3D objects or props embedded in the theatrical display. 
display is the device or the expressive support - the window of attention, e.g. the theatrical stage or the cinematic screen - used in order to perceptually access the referent, the diegetic world. Film intensely uses the variable framing in order to guide the observers' attentional cognitive capacities as an "attentional engine:" "the moving picture maker articulates her own intentions to the audience by guiding our attention" (Carroll 2008, 119-122). ${ }^{7}$ Moreover, as Carroll puts it, "the most common and paradigmatic role of variable framing is to develop and articulate movie narratives by guiding attention to critical story information, highlighting the salience of this information via indexing, scaling, and bracketing, and presenting it in a sequence that facilitates our construction of a coherent, intelligible, unified, and compelling story" (2014, 240).

Following Carroll's observations, we can further develop this theory. In the case of films, the window of attention is perceptually given (it is indexed), while in theatre, this is perceptually conducted by the observer (even if attention can be cued by bottom up inputs such as light, movement or sound). In filmic media, the experience of the body of the observer ${ }^{8}$ is a conceptual primary reference point used in order to access the detached display, the screen. The screen can represent a secondary reference point in order to acquire access to the diegesis, the imaginary world that is depicted. In cinematic displays, the body of the viewer is the grounds for the conceptualization of a screen that, in its turn, offers access to the diegetic world.

In theatrical media, the haptic experience of the conceptual primary point of reference (the observer's body) is oriented towards the diegetic space, unmediated by a material device. Awareness of one's body is the foundation of the conceptualization of the diegetic world. In a sense, in theatrical media the observer is part of the detached display, and, as a consequence, has a more immersed experience of the diegesis. Nevertheless, each medium can use, in atypical cases, technical devices borrowed from the alternate ones, e.g. screens in Romeo Castelluci's theatre and unconventionally shaped screens in Peter Greenaway's films. On the other hand, the observer, in some cases, obstructs the view of the screen and accesses to the film diegesis. This immersion creates a theatrical mental experience. Also, in the case of theatre, a selective window of attention that belongs to the observer edits stage space in a filmic fashion. However, screening a film is not a typical option for theatre and, conversely,

$7 \quad$ See also Carroll and Seeley $(2013,62)$.

8 Spectator and observer are synonyms. They are both subjective entities that cognitively process the influx of stimuli. For the purposes of this paper the conceptualizer is an observer stance cued by visual and aural expressions at work. 
bodily material immersion in the diegetic space is not a currently feasible option in films either.

\section{Medium According to Rodowick}

In The Virtual Life of Film (2007), David Rodowick criticizes Carroll's theoretical investigation and considers that, since there are multiple media and they "admit historically to qualitatively different styles and practices," they tend to represent "a set of component properties or conceptual options" $(2007,41)$. Therefore, the "medium of an art form combines multiple elements or components that can be material, instrumental, and/or formal" that are variable, and the medium can be defined without presuming an integral identity or essence uniting these elements into a whole (Rodowick 2007, 41). Rodowick borrows the notion of automatism from Stanley Cavell's The World Viewed (1971). I hold that in his essay, Rodowick criticizes Carroll's concept of detached display for being still too essentialist and materialistic, and not enough of an idealized conceptualization.

From this perspective, automatisms are both the material substance of aesthetic creation and the result of artistic practice. In this sense, automatisms are "forms, conventions, or genres that arise creatively out of the existing materials and material conditions of given art practices. In turn, they serve as potential materials or forms for future practices. Cavell calls these materials 'elements,' or fundamental acts that comprise the specific possibilities and necessities of a given medium; in doing so, they recreate the meaning of the medium with each artistic act. What constitutes these elements is unknowable prior to the creative acts of artists and the analytical observations of critics - this is why they are considered potentialities or virtualities expressed in the history of a medium and its uses" (Rodowick 2007, 42).

Automatisms act as "variable limits to subjectivity and creative agency" (for Cavell), and function as "potentialities of thought, action, or creation, and "circumscribe what subjectivity is or can be and how it is conditioned conceptually, though these conditions are neither inflexible nor invariable" (Rodowick 2007, 43). Automatisms "proliferate into individual or collective practices as new automatisms" (Rodowick 2007, 44). Thus, "in encountering automatisms as limits, artists invent new creative strategies as ways of overcoming or transforming them. But once these strategies are incorporated as elements of style, they in turn may function automatically as an aesthetic idea or strategy generating new variants on or instantiations of its concept” (Rodowick 2007, 44). 
The present essay argues in favour of a similar understanding of Jay Shieb's new practice and medium, called here, for present purposes, hypertheatre.

Our understanding of the concept of automatism is a cognitive and pragmatic one. An observer's set of beliefs regarding the practice of a medium (film/ theatre) creates expectations and conceptual content. The same applies to the difference between film and digital media. The practices involved in the production, distribution and reception of digital media construct a schematic representation of the media involved, i.e. a cognitive model (Deaca 2013, 165) and an encyclopaedic semantic definition of the media based, in certain cases, on prototypical instances that, in turn, qualify as what one describes as the meaning of the media. Defining a specific media is a conceptual operation, an instance of conceptualization that has a schematic aspect, as well as an encyclopaedic one. Digital media does not strictly represent a change in style with respect to classical film, but a change in the cognitive model expressed as a set of expectancies. In short, the audience has in mind a cognitive model and a prototypical instance of the media to be apprehended and they function as a cognitive filter of the data or stimuli at hand. Based on this mental frame, the spectator/viewer can categorize a particular experience as belonging to a certain class. Different expressive means the expressive display - cue the conceptualization that the observer can construe towards one mental structure or another. ${ }^{9}$

\section{Diegesis 1}

The theatrical performance of Sheib's hypertheatre includes living actors on a stage and an audience situated in an Italian-style stage, facing the theatrical diegesis. The stage includes actors, setting, lights, props, a series of digital cameras embedded in the fictional space and several screens situated above the stage that receive the media input from the cameras. This eclectic device cues the audience to construct a diegetic world that we can call, for analytical purposes, diegesis 1 . Several cameras are fixed on tripods and one is handled by the director [Fig. 4]. The audience can see in real time, on the screen displays hanging from the ceiling, alternative points of view of the plot unfolding on the stage. Simultaneously, the audience can follow the drama from a theatrical vantage point - since all members of the audience are pinned to their chairs and fixed to a proper optical position -, as well as from the

9 We can further develop the idea that "automatisms" or "cognitive model" are akin to the concept of "situated conceptualization" (Barsalou 1999; 2003; 2008; 2013). It is the task of future research to investigate this matter. 
point of view offered by a digital camera, which ensures an alternative view of the scene. Some screens give a complementary view of the plot and of the characters' performance - using a different angle of view, of framing and of scaling -, some give just surveillance video input from the stage location where there is no action, and a third category offers visual access to plot events that are hidden from the audience's view by means of walls and stage props. This third category inhibits access from the position of the theatre audience since the spectator will see an opaque wall on the stage that hides plot and drama, but allows access from the perspective of filmviewers. The theatrical performance contains a diegesis 1 conveyed by the blending of two channels and media: a theatre-like experience and a filmic one. Diegesis 1 is a blend formed by the integration of two media, two types of cognitive experiences of the fictional world. Aural and visual cues help maintain the spectators' focus as they witness the scene in the theatrical hall. The framed theatrical stage can be freely explored by the audience's perceptional and cognitive faculties. The cinematic framings are guided attentional engines that point out aspects of the fictional scene called diegesis 1. It is important to stress that the audience is aware of the actors, who are being displayed in the here and now together with the spectators in the theatre hall surrounding them. Therefore, diegesis 1 is accessed via the perception of the living bodies of actors, which is understood as sharing the same reality status as that of one's own body in the audience. The cognitive model of theatre includes as a defining feature the felt presence of the body of the actor and the spectator's body in the same situation or on the same ground.

\section{A System under a Dual Description: Complementarity}

Correlations - co-reference, coherence of space features - between the two media indicate a state of cognitive blending. The resulting blend is a state of fluid superposition of states. This blend is a twofold system that accepts a dual or complementary semantic description. In the view expressed in this paper - contrary to Gilles Fauconnier's theory $(1985 ; 2002 ; 2007)$ - I consider that this blend will be apprehended dynamically by an observer only through one single description (understood as a cognitive model or automatism) that represents the access gate into the blended knowledge base. ${ }^{10}$ The dominant cues give more saliency, fertility and resolution to semantic elements that compose the foregrounded medium.

10 It is not the case of an equally and equilibrated semantic integration, neither that of a metaphoric blending. Since the cases are situated on a gradual continuum, reading can shift towards a metaphorical reading. 
If cued by theatrical display features, the scene (the fictional world) inhibits the cinematic media and foregrounds its theatrical, felt experience features; and conversely, if cued by cinematic expression (variable framing: bracketing, scaling and indexing), it inhibits the theatrical experience of the scene. Cues are instructions for conceptualizations. In a sense, the overall experience is a cognitive figure of ambiguity established between figure and ground. Wittgenstein's duck versus rabbit figure is a typical example. The same set of expressive stimuli is apprehended as a multitude of cues for two alternative conceptualizations.

One consequence for our case study is that the theatrical setting - the stage with living actors in it - can be experienced as a filmic experience and, conversely, shots screened can be experienced as theatrical experiences. The mode of apprehension from one type of media is projected upon the cues from the alternative one. In other words, theatre is apprehended as film and film is apprehended as theatre. Diegesis 1 is in a superposition of states - film/theatre - that the observer, the spectator collapses into a definite and dominant media category. Digesis 1 is a reality under the "uncertainty principle." Semantic features are warped and the semantic space is tuned or shifted in order to conform to the dominant media category. Diegesis 1 can be read as a "theatre of a film" or the "film of a theatre." The dominant medium is a filter that tunes the distinctive features of the secondary one. Accordingly, diegesis 1 is a type of theatre or a type of film. In other words, it is an instance of a category defined as dominant. Diegesis 1 is a system where two defining parameters cannot be measured at the same time, and it is a dynamic conceptualization not a static bundle of features like a dictionary entry. One cannot speak about a possibility before measuring or observing - which in our case means conceptualizing - the semantic description of the artifact with the use of a definite top down cognitive model of T(heatre) or F(ilm). For the system per se, it is necessary that the measuring of a second parameter/media changes or disturbs the first parameter/media (checked before). ${ }^{11}$

A recent study elaborated by Gallant's Laboratory Attention during natural vision warps semantic representation across the human brain (Gallant 2013) can help us conceptualize this kind of semantic warping. According to Gallant, focusing the brain's attentional capacities towards a given semantic category expands the cortical representation of the target under the "magnifying glass" of attention. Cortical areas that are not initially dedicated to the focalized category

11 Richard Feyman: The Quantum Mechanical View of Reality 1 (Part 2). Workshop at Esalen Institute, 1983. Video available on YouTube: $h t t p s: / / w w w . y o u t u b e . c o m / w a t c h ? v=y t G o 85 B Z U w w$. Last accessed 23. 11. 2015. See: min. 10:23-10:25. 
tune up in order to process the task category. At the same time, dissimilar semantic categories are compressed. Attention expands the similar semantic categories even when the perceptual targets are not present. In the words of Gallant: "on the basis of neurophysiological evidence, we hypothesized that attention causes tuning changes to expand the representation of attended stimuli at the cost of unattended stimuli" $(2013,1)$. Also, Gallant asserts that "we found that many voxels across occipito-temporal and fronto-parietal cortex shifted their tuning toward the attended category. These tuning shifts expanded the representation of the attended category and of semantically related, but unattended, categories, and compressed the representation of categories that were semantically dissimilar to the target [...] these results suggest that attention dynamically alters visual representation to optimize processing of behaviorally relevant objects during natural vision" $(2013,1)$. As a general mechanism, "attention could markedly increase sensitivity for the target and improve target detection under these demanding conditions by expanding the cortical representation of behaviorally relevant categories and compressing the representation of irrelevant categories" (Gallant 2013, 1). The initial choice of the observer is to interpret the stimuli afferent to an experience as cues belonging to a type of experience will trigger an interpretive task. Once the interpretive task (the cognitive model) is active in the unconscious, a grounded conceptualization develops as a conscious and felt experience.

\section{Diegesis 2}

On the other hand, the DVD film of Shieb's hypertheatre depicts the theatrical performance that we will call diegesis 2 with the use of several types of shots. Some of them are establishing shots framed from the audience's perspective, in which the viewer can see the stage (props and dramatic action), including the screens in the theatre hall and the spectators inside the theatre hall ${ }^{12}$ [Fig. 5]. Other shots are enhanced views of diegesis 1 in close-up shots that could not be seen from the theatre audience's vantage point [Fig. 6] as the screen window is entirely covered. Camera movement and the hand-held camera of a silent director/cameraman are underlined. Editing is highlighted. Those features are thus cues for a cinematic interpretive task.

The medial artifact poses a problem of categorization to the observer. Since the content is diegesis 1, i.e. a theatrical performance, is the DVD release an atypical

12 As one can notice, theatrical observers that were outside diegesis 1 are now represented as observers inside diegesis 2 . 
theatre (the filmed version of a spectacle; a theatre accessed through the media of film), or is it an atypical film (a film depicting a spectacle)? Is the detached display a platform for a surrogate theatrical experience or a film about a theatrical event? What does one see or apprehend: the diegesis as a theatrical event or as a filmic event? [Fig. 7.] In this view, the medium is a mode of processing stimuli. The diegesis is a referent. A body of knowledge, i.e. what one knows about a medium is a filter or a series of algorithms that allow the observer to conceptualize the reference in a particular modal manner.

Diegesis 2 has an ambiguous status. Is this a theatrical event that we see? One can see the stage space and the audience space in the same shot, but this is not strange since it is a conventional framing of theatrical performances on video releases. On the other hand, inserting the audience (framed from the rear and not from the front) generates hesitation. Maybe it is not the case that this is theatre, but it is the "making of a film" instead. Schematic and theatrical settings appear in Lars von Trier's Dogville (2003). So, the DVD release is a documentary film about the process of staging pro-filmic elements for a future film. Under this interpretation, even the theatrical audience is inside a studio, as they witness the making of a film. One could also embrace a metaphorical interpretation of the DVD film, claiming that film is theatre, that is to say, that film in general is an atypical theatre. I would also like to stress the fact that in diegesis 2 the actors can be conceptualized as performed roles, i.e. unknown actors play the actors represented on the detached display of diegesis 1 in the theatrical hall. In other words, the actors that we see in the DVD film can be fictional roles, a make-believe act. This is a case of a staged installation, where both the audience and the actors are fictional entities. This option is not possible in the theatrical grounded cognition, since the body of a member of the audience does not have the reality status of a fictional being. In this interpretation, diegesis 2 incorporates both diegesis 1 and its detached display that comprises the audience, the actors and the setting.

\section{Media Entanglement}

Using an analogy as another turn of the screw, we propose to conceive of this kind of relationship established between two media and two alternative conceptions as one of entanglement between two separate imaginary worlds, called here for the sake of example diegesis 1 and diegesis $2 .{ }^{13}$ Diegesis is an imaginary world

13 As a note of caution to the reader: it is not hypothesized here that physical mechanisms described by principles such as the uncertainty principle, dual or complementary description 
apprehended specifically as a grounded conceptualization. The difference lies in the grounding, not in the imaginary features of the virtual world depicted. One definition of entanglement stipulates that we can know everything that is possible to know about a physical system composed of two subsystems and still not know all that there is to know about the individual subsystems (Susskind 2014). In other words, if an observer measures either of them, he will get random results. But, since there is a correlation between the two subsystems, if an observer makes a measurement (an experience by observation) on one, he can therefore know what the correlated state of the other is. Diegesis 1 is in a superposition of states and, until an observer experiences it, there is no collapse towards one or another subsystem. On the other hand, the two media subsystems - diegesis 1 and diegesis 2 - are correlated, since observing one entails a correlated state of the other. Diegesis 1 can be thought in terms of any of the two states or labels (the medium of theatre or the medium of film), but once the observer decides for one alternative, the whole system that contains the pair of media subsystems, i.e. theatre performance and DVD release, coheres to a definite state in which one is dominant (master) and the other is subservient (slave). In this thought experiment, features of the subordinate media are tuned in the sense of losing their specific intensity; they are inhibited and have less granularity and intensity. Put differently, each local subsystem, diegesis 1 and diegesis 2 , is in a superposition of states $(\mathrm{T} / \mathrm{F})$, but if the observer measures one, he knows with certainty the state the other is in. The procedure can also be inversely correlated. Knowing, for example, that the DVD is considered a film, automatically entails that the live performance is considered theatre (and this is valid the other way round as well). If one observer considers the play performance to be a kind of film (an atypical film), he will immediately know that the DVD release is a kind of atypical theatre.

The same correlation between two media occurs in the theatrical hall and in front of the cinema screen. Nevertheless, the superordinate category, the hypertheatre, is a system that incorporates a correlation between two nonlocal subsystems. The correlation defines a sharp distinction between the two subsystems and the two, alternate media. Hypetheatre is defined by this kind of entangled relationship, regardless of the particular kind of detached display contained by each separate subsystem or artifact. One cannot say if hypertheatre is theatre or film - even if it is based on the definition of the two media -, all that

or entanglement are ontological realities of the media, but that these concepts can be used in order to explain the subjective conceptualization of reality and thus of media. In other words, observers make a classical mental simulation of a quantum mechanical view of reality. 
can be stated is that it is an artifact which can be experienced as a conceptual trajectory that moves back and forth between two conceptualizations. Placed in an essentialist framework, hypertheatre does not have a definite status because it has included both of the above-mentioned possibilities in a paradoxical dynamic sequence. In order to have a complete description of this kind of work of art, we have to take into account both modes of existence of the object, since the specificity of hypertheatre rests on not being either of them, but being the construal of an ambiguous conceptual trajectory and consequently oscillating between them. Like in the case of the well-known duck/rabbit ambiguous figure, the conceptual description of hypertheatre has to take into account its defining indecision. The non-local artifact cannot be entirely experienced in a single perceptual dimension since, by definition, one subsystem is always non-local and accessed through memory processing, as a perceptual background. (We can represent this non-local medium with a diagram, as in Fig. 8.)

\section{Conclusion}

Apart from the automatisms defended by Rodowick, which can be seen as particular simulations (Barsalou 1999; 2003) evoked by audiovisual cues, we can assert that the dispute between $\mathrm{T}$ and $\mathrm{F}$ is constituted by the relationship of the particular body of the observer and the diegesis. Two situations are conceivable and two cognitive models are used by the observer. We start from the assumption that the observer is aware or has in its subjective area of consciousness the detached display. In the theatrical mode, the observer's focus of attention can freely explore the diegesis. The detached display, the stage in the case of theatre (T), is fused with the diegesis. The observer's side of awareness of its own body is in the side of theatrical diegesis. ${ }^{14}$ All obstacles in the observer's field of sight are considered to be inside the diegesis and situated within the reaching distance of the body, e.g. the observer can step into the diegesis and has the subconscious feeling that actors can touch him at any given time. The embodiment is translated as the projection of one's own body into the diegesis, on the scene. This is a mental frame and can be applied also to film discourse when the observer has an immersed experience of the diegesis. ${ }^{15}$ The theatrical detached display - actors,

14 This stance allows the existence of individual and collective initiation rituals (carnival, festive ceremonials).

15 Richard Schechner (2002; 2003), discussing the case of performance, draws a continuum that has at one pole the ritual, where the participant - as a fusion of spectator/actor - undergoes a change of ontological status, and at the opposite pole, the case where the spectator is situated at 
audience and setting - is part of the diegesis. ${ }^{16}$ The embodied detached display is the diegetic here and now, and it is intra-diegetic. In this sense, performances are primarily conceived by the observer as instances of reality, and, in order to be ascribed a fictional status, the use of additional cues and a supplementary mental frame is in order. Diegesis 1 is first and foremost a felt reality experience.

On the other hand, the filmic cognitive model presupposes that the display creates obstacles for the viewer situated outside the frame. That which is not visible and not graspable is off frame. The awareness area is disembodied in the sense that the focalization of the audience is not free, but guided, and the display is a screen that mediates between the observer's body - here and now - and the diegesis - there and then. In this sense, the detached display is extra-diegetic. The two sides are separated. As filmic observers of a situation, the audience can always entertain two deictic vantage points with respect to a given scene (Sweetser 2008). They can adopt an intra-diegetic vantage point or an extradiegetic one $\cdot{ }^{17}$ However, the prototypical cinematic cognitive model presupposes that the observer grounds the detached display into his/her immediate awareness area, leaving the diegetic world in the background of awareness. In our view, this kind of conceptual tuning is what defines the cinematic mode of apprehension. Diegesis 2 is first and foremost a virtual one and film has to use additional cues in order to create the felt impression of a documentary. We can also remark that this frame of mind or top-down schema can be applied either to theatre or to film displays. It is a mode of apprehension. Cues that indicate one media ( $\mathrm{T}$ or F) in a bottom-up fashion can be overwritten by this top-down schema. For example, cinematographic screens in Castellucci's theatre are still considered to be part of theatre. Ambiguous cues inside 3D audio-visual simulations are still considered by the observer as film and not theatre instantiations.

In What Cinema Is! Bazin's Quest and its Charge (2010) Dudley Andrew considers the Real and holds that the cinematic screen creates "interior interfaces that multiply states" (2010, 77). Detached displays within other detached displays "suffuse the screen with material belonging to a different level of 'reality' altogether" (Dudley, 2010, 78-79). In his view, the cinematic screen is

a distance of non-involvement as it happens in the case of shows and entertaining performances.

16 It must be pointed out that those distinctions are independent of the considerations of a documentary or fictional mode of apprehension. Understood in a documentary mode, performances imply a change of status of the participant (rituals), and read in the fictional mode, the same performances do not imply such a change.

17 Film has this dual constant vantage point as an immanent feature. Framing is an instance of the intra-diegetic display and editing is an instance of the extra-diegetic display. The two clear cut instances represent discrete opposite sides of a conceptual continuum. 
a threshold that reveals "another level of 'reality' beyond" $(2010,80)$ through which we pass towards what the "screen does and does not hold" $(2010,85)$. As a concluding remark, I will quote once again from Dudley Andrew, "the screen, then, is a threshold through which the viewer (the view-finder) passes on the way to visual experience. The threshold adds a third dimension to the frame, taken either as depth or as time" $(2010,84)$. The threshold is a manner of conceptualizing the reality simulated by the observer and is dependent upon the space/diegesis conceived. The threshold allows two heterogeneous spaces to communicate - one on the side of the observer's body and one on the side of the fictional world depicted - "stand[ing] in permanent relation to the spaces that lie on its either side” (Dudley, 2010, 85).

Hypertheatre posits a fluid function of non-collapsed states: theatre and film, a coherent Schrödinger's type of wave function. If the observer chooses to assign elsewhere either theatrical or filmic status to the present stimuli and experience, by correlation, a counter-status will be instantiated and the conceptualization will occur as a dynamic decoherence. Consequently, the temporality and dynamicity of conceptualization are contained as an emergent feature necessary for the apprehension of a static superposition of states/possibilities. The medium presupposes a conception of reality based on automatisms. The medium practiced by Scheib is therefore of a new kind and involves an entangled situation as its main distinctive feature or automatism. This constructional pattern initiates a new schema and category. Hypertheatre is a new medium; it is a twofold system containing a dynamic relation of conceptualization between two subservient media categories. ${ }^{18}$ As a final remark, keeping within the cognitive semantics framework, we can claim that new conceptual constructions can generate new media.

\section{Acknowledgements}

Thanks to Professor Ágnes Pethő, Sapientia University in Cluj-Napoca, for her helpful suggestions on an earlier draft, and my colleague Andreea Paris, University of Bucharest, for her thoughtful feedback and assistance.

18 In order to have a more detailed image of this construct, we can imagine a box containing a folded spring that has a blue and a red end. In order to find out what the box contains, we open it and the spring unfolds sometimes with the blue end towards us sometimes with the red one. Another example would be Schrödinger's box that contains a living/dead cat. 


\section{References}

Dudley, Andrew. 2010. What Cinema Is! Bazin's Quest and its Charge. West Sussex: Wiley-Blackwell.

Barsalou, Lawrence. 1999. Perceptual Symbol Systems. Behavioral and Brain Sciences vol. 22: 577-609.

Barsalou, Lawrence. 2003. Situated Simulation in the Human Conceptual System. Language and Cognitive Processes vol. 18, no. 5/6: 513-562.

Barsalou, Lawrence. 2008. Grounded Cognition. Annual Review of Psychology vol. 59: 617-645.

Barsalou, Lawrence. 2013. Mirroring as Pattern Completion Inferences within Situated Conceptualizations. Cortex vol. 49, no. 10: 2951-2953.

Bordwell, David and Kristin Thompson. 2008. Film Art: Introduction. New York: McGraw Hill.

Branigan, Edward. 1986. Diegesis and Authorship in Film. Iris vol. 7, no. 4 (Fall): $37-54$.

Buckland, Warren. 2000. The Cognitive Semiotics of Film. Cambridge: Cambridge University Press.

Carroll, Noël. 1996. Theorizing the Moving Image. Cambridge: Cambridge University Press.

Carroll, Noël. 2008. The Philosophy of Motion Pictures. Malden, MA: Blackwell Publishing.

Carroll, Noël and William P. Seeley. 2013. Cognitivism, Psychology, and Neuroscience: Movies as Attentional Engines. In Psychocinematics: Exploring Cognition at the Movies, ed. Arthur P. Shimamura, 53-75. London and New York: Routledge.

Carroll, Noël and William Seeley. 2014. Cognitive Theory and the Individual Film. The Case of Rear Window. In Cognitive Media Theory, eds. Ted Nannicelli and Paul Taberham, 235-252. New York and London: Routledge.

Cavell, Stanley. 1971. The World Viewed: Reflections on the Ontology of Film. New York: Viking Press.

Deaca, Mircea. 2013. Postfilmic Cinema. Notes and Readings about Contemporary Film. Timişoara: Editura Brumar.Fauconnier, Gilles. 1985. Mental Spaces: Aspects of Meaning Construction in Natural Language. Cambridge, Massachusetts: MIT Press and London: Bradford.

Fauconnier, Gilles and Mark Turner. 2002. The Way We Think: Conceptual Blending and the Mind's Hidden Complexities. New York: Basic Books. 
Fauconnier, Gilles. 2007. Mental Spaces. In The Oxford Handbook of Cognitive Linguistics, eds. Dirk Geeraerts and Hubert Cuyckens, 351-377. Oxford: Oxford University Press.

Fauconnier, Gilles and Mark Turner. Blending and Conceptual Integration. http:// markturner.org/blending.html, http://www.cogsci.ucsd.edu/ faucon/books. html. Last accessed 23. 11. 2015.

Gallant, Jack, Tolga Çukur, Shinji Nishimoto and Alexander G Huth. 2013. Attention during natural vision warps semantic representation across the human brain. Nature neuroscience vol. 16: 763-770, http://www.nature.com/ doifinder/10.1038/nn.3381. Last accessed 23. 11. 2015.

Gunning, Tom. 1990 [1986]. The Cinema of Attractions. Early Film, Its Spectator and the Avant-Garde. In Early Cinema: Space. Frame. Narrative, ed. Thomas Elsaesser, 56-62. London: British Film Institute.

Odin, Roger. 2000. De la fiction. Bruxelles: De Boeck Universite.

Rodowick, David. 2007. The Virtual Life of Film. Cambridge, Massachusetts: Harvard University Press.

Schechner, Richard. [1988] 2003. Performance Theory. London and New York: Routledge.

Schechner, Richard. 2002. Teaching Performance Studies. Carbondale: Southern Illinois University Press.

Susskind, Leonard. 2014. The Birth of the Universe and the Origin of Laws of Physics, Lecture 3: Entanglement, at Cornell University, 28 April-1 May, 2014. http://www.cornell.edu/video/playlist/leonard-susskind-messenger-lectures; https://www.youtube.com/watch?v=WFigQYnqiYw. Last accessed 23. 11. 2015.

Sweetser, Eve. 2008. Viewpoint and Perspective in Language and Gesture. 9 Crawford Hall (Inamori Center). https://www.youtube.com/watch?v=EGxoAIQOMM. Last accessed 26. 03. 2008. 


\section{List of Figures}

Figure 1. This Place is a Desert. Screenshot from the DVD release that contains cinematic displays, theatrical display and the audience in the foreground of the image.

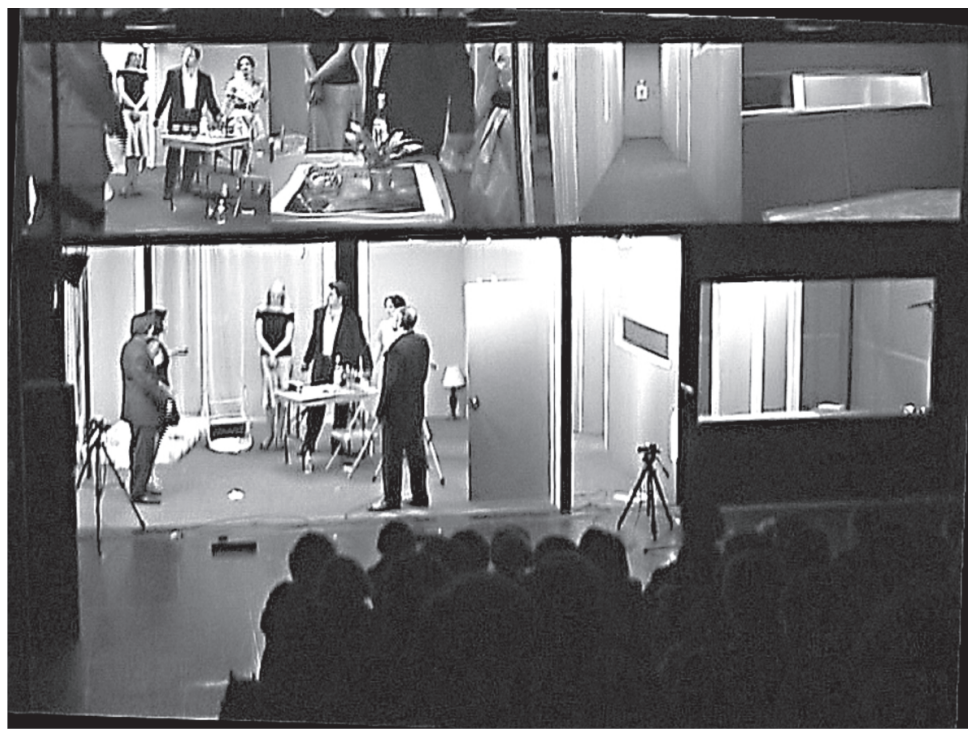

Figure 2. This Place is a Desert. The frame composition is structured in the cinematic depth of the field (like in the films of Antonioni, Welles).

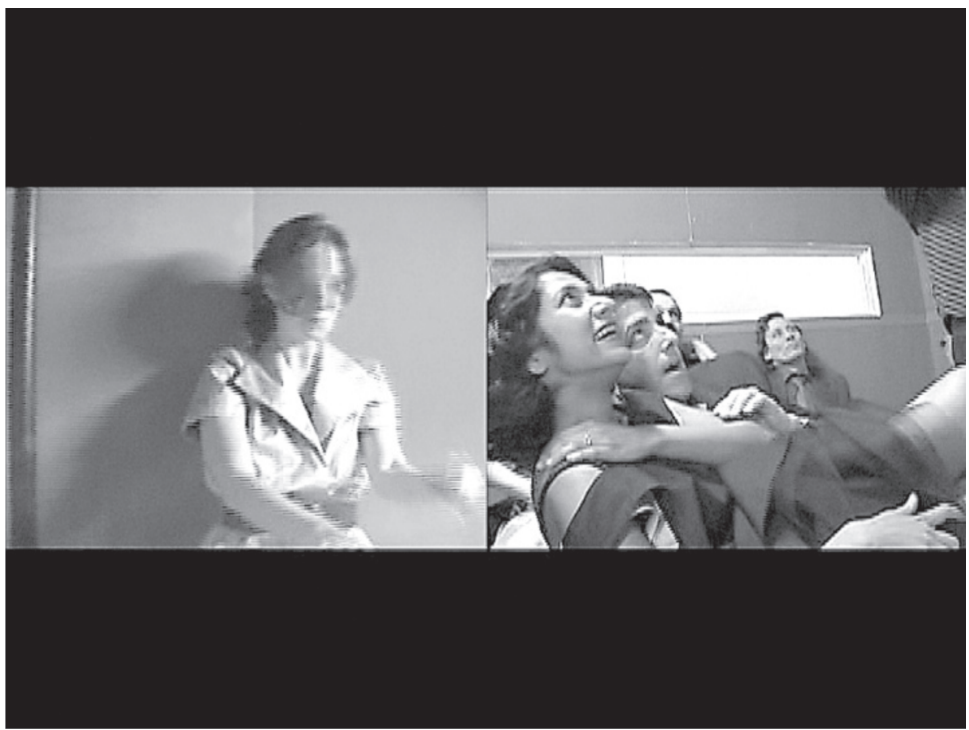


Figure 3. This Place is a Desert. Frame composition that replays Timecode (Mike Figgis, 2000).

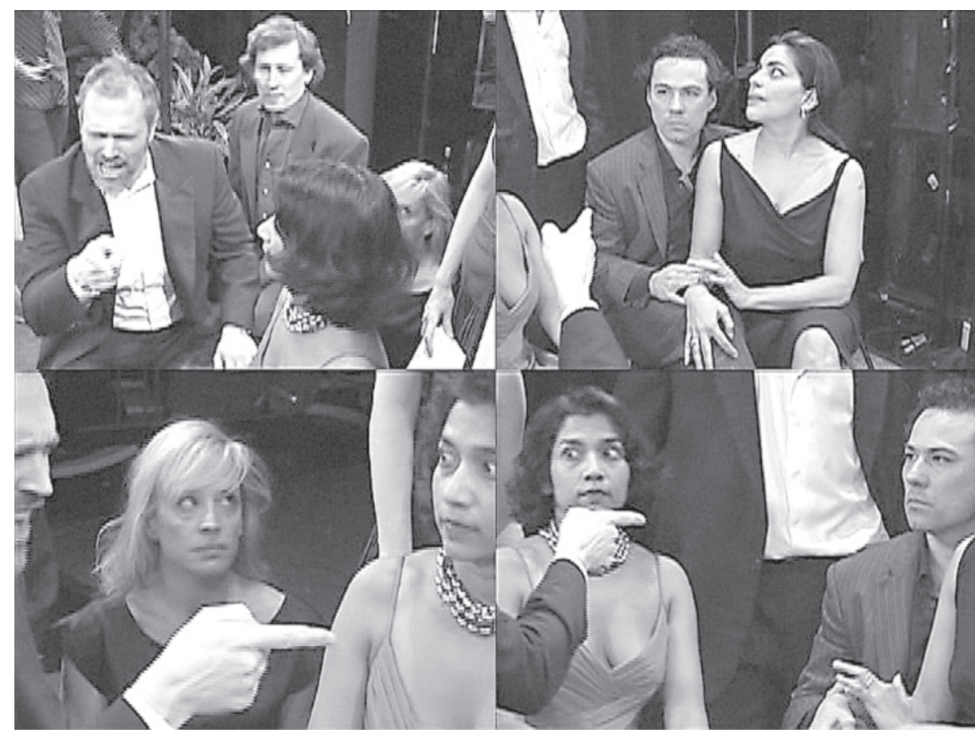

Figure 4. This Place is a Desert. In the right quadrant of the image, the cinematic observer can see the mirror reflection of the director embedded in the theatrical diegesis and hand-holding a digital camera that feeds the cinematic image.

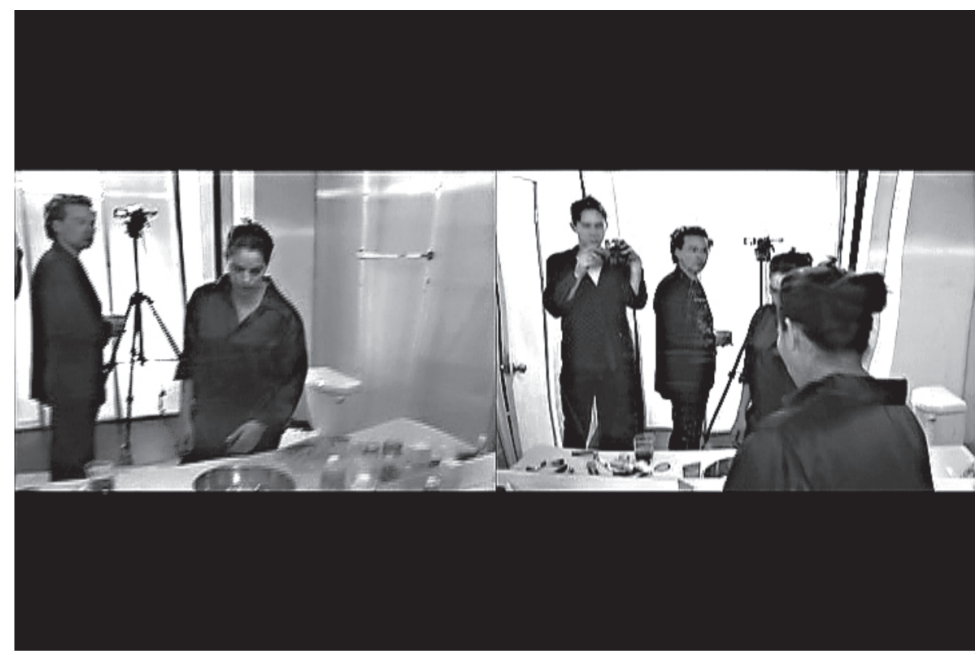


Figure 5. This Place is a Desert. The theatrical audience is part of the cinematic diegesis.

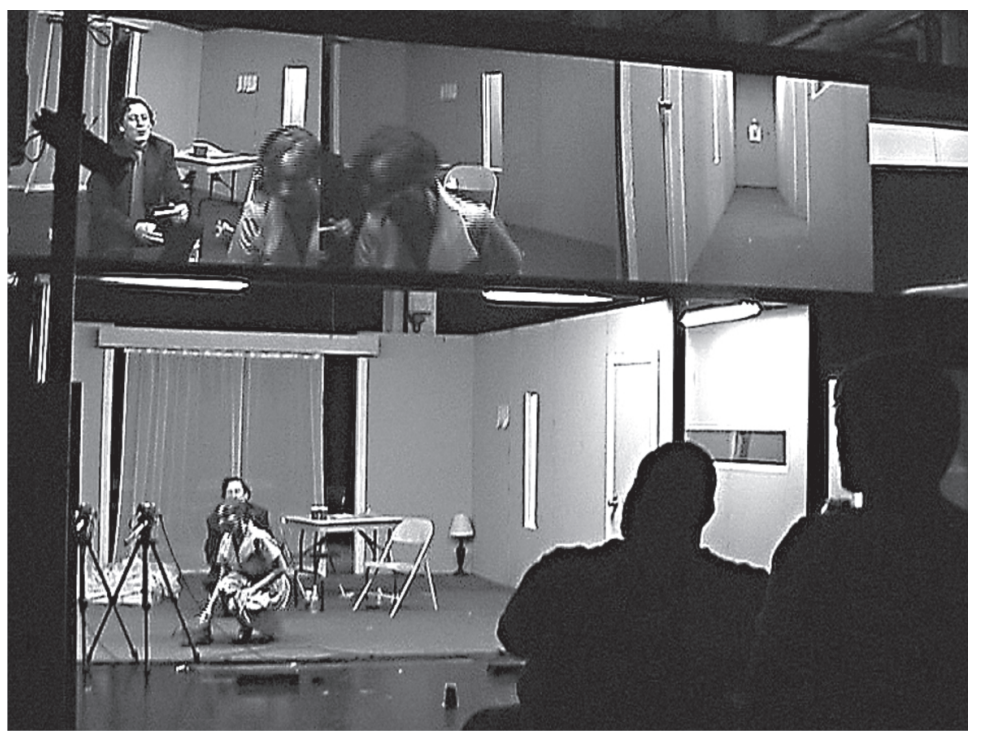

Figure 6. World of Wires. In the right quadrant of the image, we can see an image projected on a screen in the theatrical hall but recorded from a vantage point situated in the rear end of the theatrical scene. On the left side of the image, the screen is destroyed by the actors.

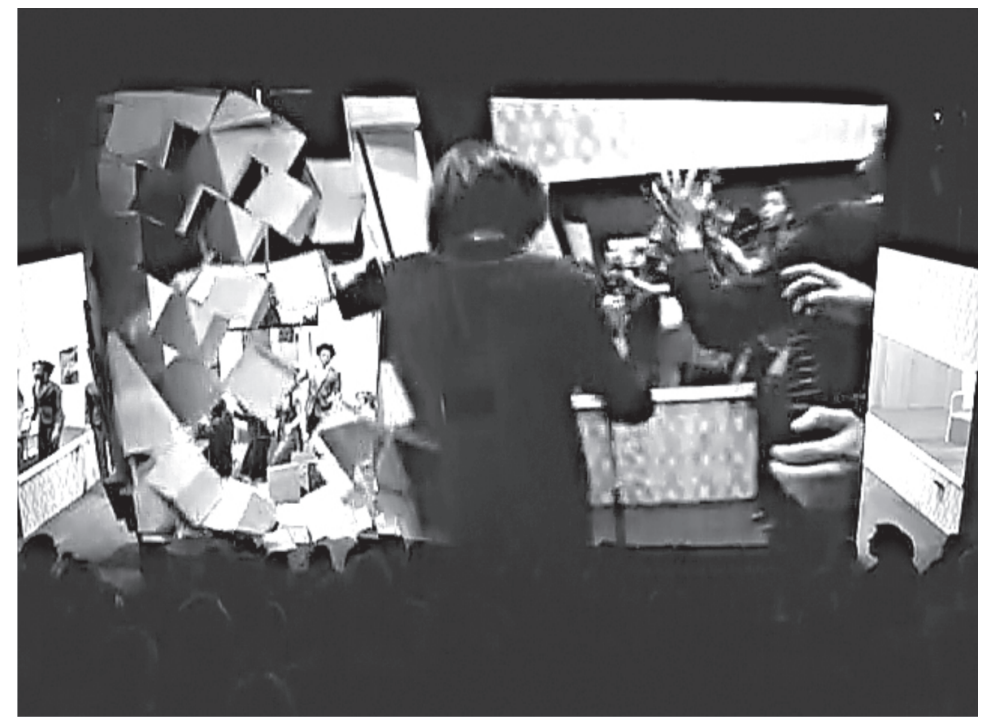


Figure 7. World of Wires. On the silkscreen, in the theatrical hall, there is an image, recorded from behind the scene, of a character who destroys the screen upon which his image is projected.

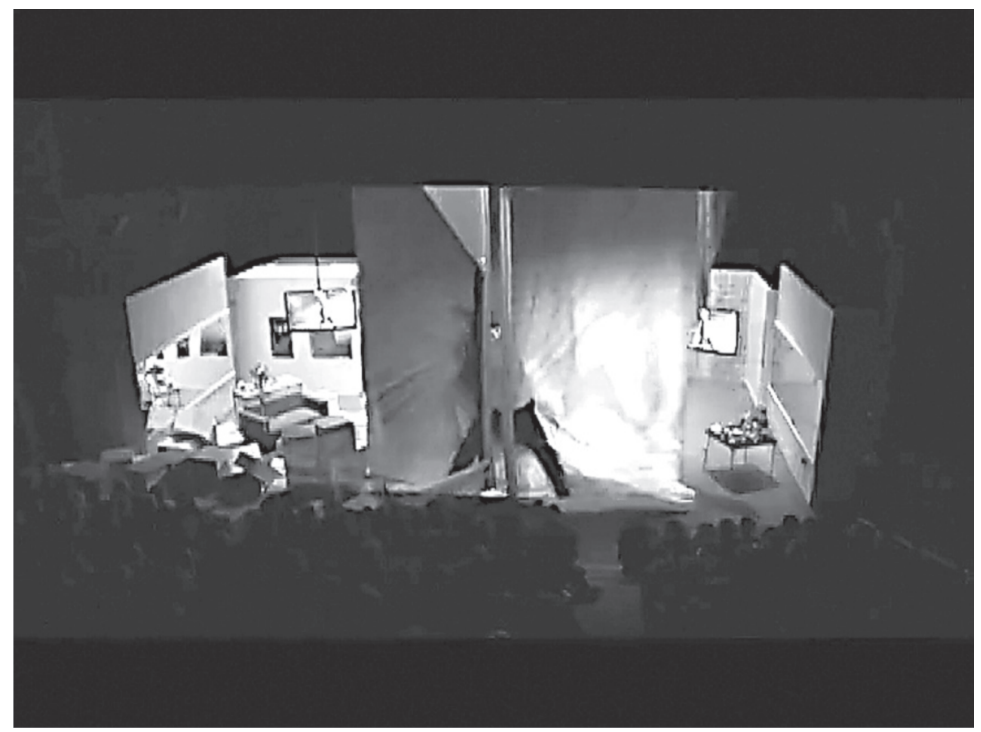

Figure 8. Diagram representing the relations between theatre $(\mathrm{T})$ and film $(\mathrm{F})$.

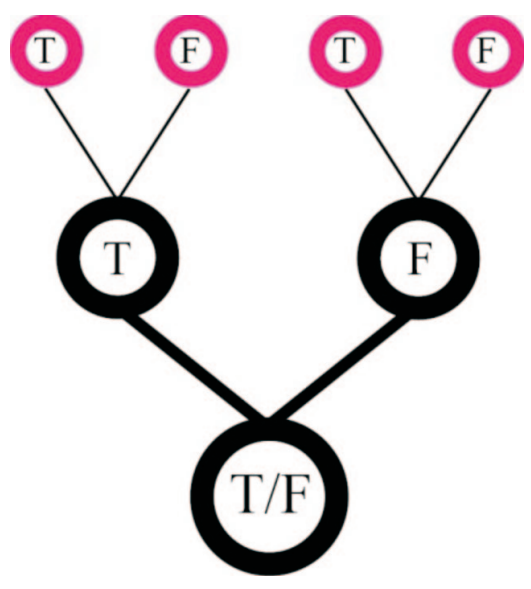

